\title{
Ulam stability of functional equations in 2-Banach spaces via the fixed point method
}

\author{
Krzysztof Ciepliński®
}

\begin{abstract}
Using the fixed point method, we prove the Ulam stability of two general functional equations in several variables in 2-Banach spaces. As corollaries from our main results, some outcomes on the stability of a few known equations being special cases of the considered ones will be presented. In particular, we extend several recent results on the Ulam stability of functional equations in 2-Banach spaces.
\end{abstract}

Mathematics Subject Classification. 39B82, 47H10, 39B72.

Keywords. Ulam stability, fixed point method, 2-Banach space, Cauchy equation, Jordan-von Neumann equation, linear functional equation.

\section{Background and motivation}

The question about an error one commits replacing an object with some properties by an object satisfying them only approximately is natural and interesting both in mathematics and in many other scientific investigations. To deal with it the notion of the Ulam stability can be used.

Let us recall that in 1940 Ulam, during his talk at the University of Wisconsin, posed the problem of the stability of group homomorphisms, i.e. the Cauchy functional equation

$$
f(x+y)=f(x)+f(y),
$$

and Hyers in [32] gave its solution in the case of Banach spaces. Hyers' result was extended by Aoki in [4] and Rassias in [44] (see also a remark of Bourgin in [8]) in the following way.

Let $E_{1}$ and $E_{2}$ be Banach spaces, $\varepsilon \geq 0, p \in[0,1)$ and $f: E_{1} \rightarrow E_{2}$ be a mapping with

$$
\|f(x+y)-f(x)-f(y)\| \leq \varepsilon\left(\|x\|^{p}+\|y\|^{p}\right), \quad x, y \in E_{1} .
$$


Then there is a unique additive mapping, i.e. a solution of Eq. (1), a: $E_{1} \rightarrow$ $E_{2}$ such that

$$
\|f(x)-a(x)\| \leq \frac{2 \varepsilon}{2-2^{p}}\|x\|^{p}, \quad x \in E_{1} .
$$

Next, Rassias noticed that a similar result is also valid for $p<0$, and Gajda in [29] proved it for $p>1$ and provided an example showing that for $p=1$ such an outcome is not possible.

In recent years, the Ulam stability of various (among others functional, difference, differential and integral) equations and other objects (for example groups, $C^{*}$-algebras and flows) has been intensively studied (see for instance $[6,7,11,12,25,27,30,33,35,38,39]$ and references therein).

In this paper, we prove the Ulam stability of two general functional equations in several variables in 2-Banach spaces. We also get, as corollaries from the main results, some outcomes on the stability of a few known equations being special cases of the considered ones. In particular, we thus extend several recent results on the stability of functional equations in 2-Banach spaces which were published in $[3,10,14,15,18,21,22,45]$.

Let us yet mention that in the proofs of our main results a variant of the fixed point method is applied. More precisely, we use a fixed point theorem of Diaz and Margolis from [24]. More information about the fixed point method one can find in $[9,17]$.

Throughout the paper $\mathbb{N}$ stands for the set of all positive integers and we put $\mathbb{N}_{0}:=\mathbb{N} \cup\{0\}$. Moreover, we assume that $n \in \mathbb{N}, X$ is a linear space over the field $\mathbb{F}$, and $Y$ is a linear space over the field $\mathbb{K}$.

\section{Introduction}

Let $a_{11}, a_{12}, \ldots, a_{n 1}, a_{n 2} \in \mathbb{F}, a_{1, j_{1}, \ldots, j_{n}}, \ldots, a_{n, j_{1}, \ldots, j_{n}} \in \mathbb{F}$ for $j_{1}, \ldots, j_{n} \in$ $\{-1,1\}$ and $A_{i_{1}, \ldots, i_{n}} \in \mathbb{K}$ for $i_{1}, \ldots, i_{n} \in\{1,2\}$ be given scalars. Put, moreover,

$$
A:=\sum_{i_{1}, \ldots, i_{n} \in\{1,2\}} A_{i_{1}, \ldots, i_{n}}
$$

and assume that $A \neq 0$.

We deal with the following functional equations:

$$
\begin{aligned}
& f\left(a_{11} x_{11}+a_{12} x_{12}, \ldots, a_{n 1} x_{n 1}+a_{n 2} x_{n 2}\right) \\
& \quad=\sum_{i_{1}, \ldots, i_{n} \in\{1,2\}} A_{i_{1}, \ldots, i_{n}} f\left(x_{1 i_{1}}, \ldots, x_{n i_{n}}\right)
\end{aligned}
$$

and

$$
\begin{aligned}
& \sum_{j_{1}, \ldots, j_{n} \in\{-1,1\}} f\left(a_{1, j_{1}, \ldots, j_{n}}\left(x_{11}+j_{1} x_{12}\right), \ldots, a_{n, j_{1}, \ldots, j_{n}}\left(x_{n 1}+j_{n} x_{n 2}\right)\right) \\
& =\sum_{i_{1}, \ldots, i_{n} \in\{1,2\}} A_{i_{1}, \ldots, i_{n}} f\left(x_{1 i_{1}}, \ldots, x_{n i_{n}}\right) .
\end{aligned}
$$


Equation (2) was very recently introduced in [20], and it generalizes among others the known functional equations

$$
\begin{gathered}
f\left(x_{11}+x_{12}, \ldots, x_{n 1}+x_{n 2}\right)=\sum_{i_{1}, \ldots, i_{n} \in\{1,2\}} f\left(x_{1 i_{1}}, \ldots, x_{n i_{n}}\right), \\
\quad f\left(\frac{1}{2} x_{11}+\frac{1}{2} x_{12}, \ldots, \frac{1}{2} x_{n 1}+\frac{1}{2} x_{n 2}\right)=\sum_{i_{1}, \ldots, i_{n} \in\{1,2\}} \frac{1}{2^{n}} f\left(x_{1 i_{1}}, \ldots, x_{n i_{n}}\right)
\end{gathered}
$$

and, for $n \geq 2$ and $1 \leq k<n$,

$$
\begin{gathered}
f\left(x_{11}+x_{12}, \ldots, x_{k 1}+x_{k 2}, \frac{1}{2} x_{k+11}+\frac{1}{2} x_{k+12}, \ldots, \frac{1}{2} x_{n 1}+\frac{1}{2} x_{n 2}\right) \\
=\sum_{i_{1}, \ldots, i_{n} \in\{1,2\}} \frac{1}{2^{n-k}} f\left(x_{1 i_{1}}, \ldots, x_{n i_{n}}\right)
\end{gathered}
$$

(see $[5,16,43]$, and $[20]$ for more details).

Let us also mention that the case $n=2$ was studied in [19], and for $n=1$, we get the linear functional equation

$$
f\left(a_{1} x_{1}+a_{2} x_{2}\right)=A_{1} f\left(x_{1}\right)+A_{2} f\left(x_{2}\right),
$$

which includes, among others, the Cauchy equation and the famous Jensen functional equation

$$
f\left(\frac{x+y}{2}\right)=\frac{f(x)+f(y)}{2} .
$$

A lot of information about the Cauchy and Jensen equations as well as their applications and stability can be found in [1,35-37], whereas some very recent stability outcomes on Eq. (6) were published for instance in $[2,42]$ (see also [3], where the stability of yet another special case of (6) was considered in 2-Banach spaces).

A particular case of Eq. (2) is the functional equation

$$
\begin{aligned}
& \sum_{j_{1}, \ldots, j_{n} \in\{-1,1\}} f\left(x_{11}+j_{1} x_{12}, \ldots, x_{n 1}+j_{n} x_{n 2}\right) \\
& =\sum_{i_{1}, \ldots, i_{n} \in\{1,2\}} 2^{n} f\left(x_{1 i_{1}}, \ldots, x_{n i_{n}}\right),
\end{aligned}
$$

which (see $[34,47]$, where its Ulam stability is also studied) characterizes the so-called $n$-quadratic mappings. For $n=1$ it leads to the well-known Jordan-von Neumann equation

$$
q(x+y)+q(x-y)=2 q(x)+2 q(y) .
$$

A lot of information about solutions of the Jordan-von Neumann equation (i.e. quadratic mappings), its applications and Ulam stability can be found in $[35,36]$ (see also $[23,46]$ for some classical stability results on this equation). On the other hand, the case $n=2$ was considered in [40].

Another particular case of Eq. (3), i.e. the functional equation

$$
\begin{aligned}
f( & \left.x_{11}+x_{12}, x_{21}+x_{22}\right)+f\left(x_{11}+x_{12}, x_{21}-x_{22}\right) \\
& +f\left(x_{11}-x_{12}, x_{21}+x_{22}\right)+f\left(x_{11}-x_{12}, x_{21}-x_{22}\right) \\
= & A_{1,1} f\left(x_{11}, x_{21}\right)+A_{1,2} f\left(x_{11}, x_{22}\right) \\
\quad & +A_{2,1} f\left(x_{12}, x_{21}\right)+A_{2,2} f\left(x_{12}, x_{22}\right),
\end{aligned}
$$


with $A_{1,1}, A_{1,2}, A_{2,1}, A_{2,2} \geq 0$, was very recently investigated in [26], where its characterizations and representations of set-valued solutions are obtained.

\section{Preliminaries}

Let us recall that a 2-normed space was defined by Gähler in [28] as a pair $(X,\|\cdot, \cdot\|)$, where $X$ is an at least two-dimensional real linear space and $\|\cdot, \cdot\|$ : $X \times X \rightarrow[0, \infty)$ is a mapping such that for any $\alpha \in \mathbb{R}, x, y, z \in X$, we have

$$
\begin{aligned}
\|x, y\| & =0 \Longleftrightarrow x \text { and } y \text { are linearly dependent, } \\
\|x, y\| & =\|y, x\| \\
\|x, y+z\| & \leq\|x, y\|+\|x, z\| \\
\|\alpha x, y\| & =|\alpha|\|x, y\| .
\end{aligned}
$$

The following known definitions and facts will be used in the sequel.

Let $\left(x_{k}\right)_{k \in \mathbb{N}}$ be a sequence of elements of a 2 -normed space $(X,\|\cdot, \cdot\|)$. This sequence is called Cauchy if there exist linearly independent $y, z \in X$ for which

$$
\lim _{n, m \rightarrow \infty}\left\|x_{n}-x_{m}, y\right\|=0=\lim _{n, m \rightarrow \infty}\left\|x_{n}-x_{m}, z\right\|,
$$

while $\left(x_{n}\right)_{n \in \mathbb{N}}$ is said to be convergent provided there is an $x \in X$ with

$$
\lim _{k \rightarrow \infty}\left\|x_{k}-x, y\right\|=0, \quad y \in X .
$$

In the latter case, the element $x$ is called the limit of the sequence $\left(x_{k}\right)_{k \in \mathbb{N}}$ and we denote it by $\lim _{k \rightarrow \infty} x_{k}$. Clearly, every convergent sequence possesses a unique limit. Moreover, the standard properties of the limit of a sum and a scalar product hold.

By a 2-Banach space we mean a 2-normed space such that each its Cauchy sequence is convergent.

Remark 1. Assume that $(X,\|\cdot, \cdot\|)$ is a 2 -normed space and $\left(x_{k}\right)_{k \in \mathbb{N}}$ is a sequence of elements of $X$. Then

(i) if $x \in X$ and $\|x, y\|=0$ for any $y \in X$, then $x=0$;

(ii) if the sequence $\left(x_{k}\right)_{k \in \mathbb{N}}$ is convergent, then

$$
\lim _{k \rightarrow \infty}\left\|x_{k}, y\right\|=\left\|\lim _{k \rightarrow \infty} x_{k}, y\right\|, \quad y \in X .
$$

Let us also recall that a pair $(G, d)$ is said to be a generalized metric space provided $G$ is a nonempty set and $d: G \times G \rightarrow[0, \infty]$ is a function satisfying the standard metric axioms.

The following result from [24] plays a crucial role in the proof of the main results of this paper.

Proposition 2. Assume that $(\mathcal{G}, d)$ is a complete generalized metric space and $T: \mathcal{G} \rightarrow \mathcal{G}$ is a strictly contractive operator with the Lipschitz constant $L<1$. If there are $n_{0} \in \mathbb{N}_{0}$ and $x \in \mathcal{G}$ such that $d\left(T^{n_{0}+1} x, T^{n_{0}} x\right)<\infty$, then:

(i) the sequence $\left(T^{j} x\right)_{j \in \mathbb{N}}$ is convergent, and its limit $x^{*}$ is a fixed point of the operator $T$; 
(ii) $x^{*}$ is the unique fixed point of $T$ in the set

$$
\mathcal{G}^{*}:=\left\{y \in \mathcal{G}: d\left(T^{n_{0}} x, y\right)<\infty\right\}
$$

(iii) if $y \in \mathcal{G}^{*}$, then

$$
d\left(y, x^{*}\right) \leq \frac{1}{1-L} d(T y, y)
$$

\section{Main results}

In this section, we prove the Ulam stability of functional equations (2) and (3). We start with the first of them.

Theorem 3. Assume that $Y$ is a 2-Banach space, $|A|>1$ and $\varepsilon>0$. If $f: X^{n} \rightarrow Y$ is a function satisfying

$$
\begin{aligned}
& \| f\left(a_{11} x_{11}+a_{12} x_{12}, \ldots, a_{n 1} x_{n 1}+a_{n 2} x_{n 2}\right) \\
& \quad-\sum_{i_{1}, \ldots, i_{n} \in\{1,2\}} A_{i_{1}, \ldots, i_{n}} f\left(x_{1 i_{1}}, \ldots, x_{n i_{n}}\right), y \| \leq \varepsilon
\end{aligned}
$$

for $\left(x_{11}, x_{12}, \ldots, x_{n 1}, x_{n 2}\right) \in X^{2 n}$ and $y \in Y$, then there exists a unique solution $F: X^{n} \rightarrow Y$ of Eq. (2) for which

$$
\begin{gathered}
\left\|f\left(x_{1}, \ldots, x_{n}\right)-F\left(x_{1}, \ldots, x_{n}\right), y\right\| \leq \frac{\varepsilon}{|A|-1}, \\
\left(x_{1}, \ldots, x_{n}\right) \in X^{n}, y \in Y .
\end{gathered}
$$

The mapping $F$ is given by

$$
F\left(x_{1}, \ldots, x_{n}\right):=\lim _{j \rightarrow \infty} \frac{f\left(a_{1}^{j} x_{1}, \ldots, a_{n}^{j} x_{n}\right)}{A^{j}}, \quad\left(x_{1}, \ldots, x_{n}\right) \in X^{n} .
$$

Proof. Let us consider a complete generalized metric space $(\mathcal{G}, d)$, where

$$
\mathcal{G}:=Y^{X^{n}}
$$

and

$$
\begin{aligned}
d(g, h) & :=\inf \left\{C \in[0, \infty]:\left\|g\left(x_{1}, \ldots, x_{n}\right)-h\left(x_{1}, \ldots, x_{n}\right), y\right\|\right. \\
& \left.\leq C \varepsilon,\left(x_{1}, \ldots, x_{n}\right) \in X^{n}, y \in Y\right\}, \quad g, h \in \mathcal{G} .
\end{aligned}
$$

Put also

$$
a_{i}:=a_{i 1}+a_{i 2}, \quad i \in\{1, \ldots, n\}
$$

and

$$
\operatorname{Tg}\left(x_{1}, \ldots, x_{n}\right):=\frac{1}{A} g\left(a_{1} x_{1}, \ldots, a_{n} x_{n}\right), \quad g \in \mathcal{G},\left(x_{1}, \ldots, x_{n}\right) \in X^{n} .
$$


We show that $T: \mathcal{G} \rightarrow \mathcal{G}$ is a strictly contractive operator with the Lipschitz constant $\frac{1}{|A|}$. To do this, fix $g, h \in \mathcal{G},\left(x_{1}, \ldots, x_{n}\right) \in X^{n}, y \in Y$ and $C_{g, h} \in$ $[0, \infty]$ with $d(g, h) \leq C_{g, h}$. Then

$$
\left\|g\left(x_{1}, \ldots, x_{n}\right)-h\left(x_{1}, \ldots, x_{n}\right), y\right\| \leq C_{g, h} \varepsilon,
$$

and consequently

$$
\begin{aligned}
& \left\|\operatorname{Tg}\left(x_{1}, \ldots, x_{n}\right)-\operatorname{Th}\left(x_{1}, \ldots, x_{n}\right), y\right\| \\
& \quad=\frac{1}{|A|}\left\|g\left(a_{1} x_{1}, \ldots, a_{n} x_{n}\right)-h\left(a_{1} x_{1}, \ldots, a_{n} x_{n}\right), y\right\| \leq \frac{1}{|A|} C_{g, h} \varepsilon .
\end{aligned}
$$

Therefore, $d(T g, T h) \leq \frac{1}{|A|} C_{g, h}$ and $d(T g, T h) \leq \frac{1}{|A|} d(g, h)$, as claimed.

Let us next observe that from (9) it follows that

$$
\begin{array}{rl}
\| T & f\left(x_{1}, \ldots, x_{n}\right)-f\left(x_{1}, \ldots, x_{n}\right), y \| \\
\quad=\left\|\frac{1}{A} f\left(a_{1} x_{1}, \ldots, a_{n} x_{n}\right)-f\left(x_{1}, \ldots, x_{n}\right), y\right\| \leq \frac{1}{|A|} \varepsilon,
\end{array}
$$

and thus

$$
d(T f, f) \leq \frac{1}{|A|}<\infty .
$$

We can now apply Proposition 2 for the space $(\mathcal{G}, d)$, the operator $T, L=\frac{1}{|A|}$, $n_{0}=0$ and $x=f$ to deduce that the sequence $\left(T^{j} f\right)_{j \in \mathbb{N}}$ is convergent in $(\mathcal{G}, d)$ and its limit $F$ is a fixed point of $T$.

Thus,

$$
F\left(x_{1}, \ldots, x_{n}\right)=\lim _{j \rightarrow \infty} T^{j} f\left(x_{1}, \ldots, x_{n}\right)
$$

and

$$
\frac{1}{A} F\left(a_{1} x_{1}, \ldots, a_{n} x_{n}\right)=F\left(x_{1}, \ldots, x_{n}\right) .
$$

Since, by induction, we also have

$$
T^{j} f\left(x_{1}, \ldots, x_{n}\right)=\frac{1}{A^{j}} f\left(a_{1}^{j} x_{1}, \ldots, a_{n}^{j} x_{n}\right), \quad j \in \mathbb{N}
$$

(11) follows.

Next, note that obviously $f \in \mathcal{G}^{*}$, and therefore, Proposition 2(iii) and (13) imply

$$
d(f, F) \leq \frac{1}{1-\frac{1}{|A|}} d(T f, f) \leq \frac{1}{|A|-1},
$$

which proves (10).

Let us now observe that from (9) we get

$$
\begin{aligned}
& \| \frac{f\left(a_{1}^{j}\left(a_{11} x_{11}+a_{12} x_{12}\right), \ldots, a_{n}^{j}\left(a_{n 1} x_{n 1}+a_{n 2} x_{n 2}\right)\right)}{A^{j}} \\
& \quad-\sum_{i_{1}, \ldots, i_{n} \in\{1,2\}} A_{i_{1}, \ldots, i_{n}} \frac{f\left(a_{1}^{j} x_{\left.1 i_{1}, \ldots, a_{n}^{j} x_{n i_{n}}\right)}\right.}{A^{j}}, y \| \leq \frac{\varepsilon}{|A|^{j}}
\end{aligned}
$$


for $\left(x_{11}, x_{12}, \ldots, x_{n 1}, x_{n 2}\right) \in X^{2 n}, y \in Y$ and $j \in \mathbb{N}_{0}$. Letting $j \rightarrow \infty$, and applying (11) and Remark 1(ii) we deduce hence that

$$
\begin{aligned}
& \| F\left(a_{11} x_{11}+a_{12} x_{12}, \ldots, a_{n 1} x_{n 1}+a_{n 2} x_{n 2}\right) \\
& \quad-\sum_{i_{1}, \ldots, i_{n} \in\{1,2\}} A_{i_{1}, \ldots, i_{n}} F\left(x_{1 i_{1}}, \ldots, x_{n i_{n}}\right), y \| \leq 0
\end{aligned}
$$

for $\left(x_{11}, x_{12}, \ldots, x_{n 1}, x_{n 2}\right) \in X^{2 n}$ and $y \in Y$, and thus by Remark 1(i) we see that the mapping $F: X^{n} \rightarrow Y$ is a solution of functional equation (2).

Let us finally suppose that $F^{\prime}: X^{n} \rightarrow Y$ is a solution of Eq. (2) fulfilling inequality (10). Then $F^{\prime}$ satisfies (15), and therefore, it is a fixed point of the operator $T$. Furthermore, by (10), we obtain

$$
d\left(f, F^{\prime}\right) \leq \frac{1}{|A|-1}<\infty
$$

and consequently $F^{\prime} \in \mathcal{G}^{*}$. Proposition 2(ii) now shows that $F^{\prime}=F$.

Next, we show the stability of Eq. (3).

Theorem 4. Assume that $Y$ is a 2-Banach space, $|A|>1$ and $\varepsilon>0$. If $f$ : $X^{n} \rightarrow Y$ is a function such that $f\left(x_{1}, \ldots, x_{n}\right)=0$ for any $\left(x_{1}, \ldots, x_{n}\right) \in X^{n}$ with at least one component which is equal to zero and

$$
\begin{aligned}
& \| \sum_{j_{1}, \ldots, j_{n} \in\{-1,1\}} f\left(a_{1, j_{1}, \ldots, j_{n}}\left(x_{11}+j_{1} x_{12}\right), \ldots, a_{n, j_{1}, \ldots, j_{n}}\left(x_{n 1}+j_{n} x_{n 2}\right)\right) \\
& \quad-\sum_{i_{1}, \ldots, i_{n} \in\{1,2\}} A_{i_{1}, \ldots, i_{n}} f\left(x_{1 i_{1}}, \ldots, x_{n i_{n}}\right), y \| \leq \varepsilon
\end{aligned}
$$

for $\left(x_{11}, x_{12}, \ldots, x_{n 1}, x_{n 2}\right) \in X^{2 n}$ and $y \in Y$, then there exists a unique solution $F: X^{n} \rightarrow Y$ of Eq. (3) such that inequality (10) holds and $F\left(x_{1}, \ldots, x_{n}\right)=$ 0 for any $\left(x_{1}, \ldots, x_{n}\right) \in X^{n}$ with at least one component which is equal to zero. The mapping $F$ is given by

$$
\begin{aligned}
F\left(x_{1}, \ldots, x_{n}\right)= & \lim _{j \rightarrow \infty} \frac{1}{A^{j}} f\left(\left(2 a_{1,1, \ldots, 1}\right)^{j} x_{1}, \ldots,\left(2 a_{n, 1, \ldots, 1}\right)^{j} x_{n}\right), \\
& \left(x_{1}, \ldots, x_{n}\right) \in X^{n} .
\end{aligned}
$$

Proof. Let us consider a complete generalized metric space $(\mathcal{G}, d)$, where

$$
\begin{aligned}
\mathcal{G}:= & \left\{f: X^{n} \rightarrow Y: f\left(x_{1}, \ldots, x_{n}\right)=0 \text { for any }\left(x_{1}, \ldots, x_{n}\right) \in X^{n}\right. \\
& \text { with at least one component which is equal to zero }\}
\end{aligned}
$$

and $d$ is as in the proof of Theorem 3. Put also

$$
\begin{gathered}
\operatorname{Tg}\left(x_{1}, \ldots, x_{n}\right):=\frac{1}{A} g\left(2 a_{1,1, \ldots, 1} x_{1}, \ldots, 2 a_{n, 1, \ldots, 1} x_{n}\right), \\
g \in \mathcal{G},\left(x_{1}, \ldots, x_{n}\right) \in X^{n} .
\end{gathered}
$$


We show that $T: \mathcal{G} \rightarrow \mathcal{G}$ is a strictly contractive operator with the Lipschitz constant $\frac{1}{|A|}$. To do this, fix $g, h \in \mathcal{G},\left(x_{1}, \ldots, x_{n}\right) \in X^{n}, y \in Y$ and $C_{g, h} \in$ $[0, \infty]$ with $d(g, h) \leq C_{g, h}$. Then (12) holds, whence

$$
\begin{aligned}
& \left\|\operatorname{Tg}\left(x_{1}, \ldots, x_{n}\right)-T h\left(x_{1}, \ldots, x_{n}\right), y\right\| \\
& \quad=\frac{1}{|A|}\left\|g\left(2 a_{1,1, \ldots, 1} x_{1}, \ldots, 2 a_{n, 1, \ldots, 1} x_{n}\right)-h\left(2 a_{1,1, \ldots, 1} x_{1}, \ldots, 2 a_{n, 1, \ldots, 1} x_{n}\right), y\right\| \\
& \quad \leq \frac{1}{|A|} C_{g, h} \varepsilon,
\end{aligned}
$$

and thus $T$ is strictly contractive with the constant $\frac{1}{|A|}$.

Let us next observe that from (16) and the fact that $f\left(x_{1}, \ldots, x_{n}\right)=0$ for any $\left(x_{1}, \ldots, x_{n}\right) \in X^{n}$ with at least one component which is equal to zero it follows that

$$
\begin{aligned}
& \left\|T f\left(x_{1}, \ldots, x_{n}\right)-f\left(x_{1}, \ldots, x_{n}\right), y\right\| \\
& \quad=\left\|\frac{1}{A} f\left(2 a_{1,1, \ldots, 1} x_{1}, \ldots, 2 a_{n, 1, \ldots, 1} x_{n}\right)-f\left(x_{1}, \ldots, x_{n}\right), y\right\| \leq \frac{\varepsilon}{|A|},
\end{aligned}
$$

and thus (13) holds true. From Proposition 2, we see that the sequence $\left(T^{j} f\right)_{j \in \mathbb{N}}$ is convergent in $(\mathcal{G}, d)$ and its limit $F$ is a fixed point of $T$.

Therefore, we get (14) and

$$
\frac{1}{A} F\left(2 a_{1,1, \ldots, 1} x_{1}, \ldots, 2 a_{n, 1, \ldots, 1} x_{n}\right)=F\left(x_{1}, \ldots, x_{n}\right) .
$$

Since, by induction, we also have

$$
T^{j} f\left(x_{1}, \ldots, x_{n}\right)=\frac{1}{A^{j}} f\left(\left(2 a_{1,1, \ldots, 1}\right)^{j} x_{1}, \ldots,\left(2 a_{n, 1, \ldots, 1}\right)^{j} x_{n}\right), \quad j \in \mathbb{N},
$$

(17) follows.

Let us now observe that inequality (10) can be shown as in the proof of Theorem 3.

Next, from (16) we get

$$
\begin{aligned}
& \| \sum_{j_{1}, \ldots, j_{n} \in\{-1,1\}} \frac{1}{A^{j}} f\left(\left(2 a_{1,1, \ldots, 1}\right)^{j} a_{1, j_{1}, \ldots, j_{n}}\left(x_{11}+j_{1} x_{12}\right), \ldots,\right. \\
& \left.\quad\left(2 a_{n, 1, \ldots, 1}\right)^{j} a_{n, j_{1}, \ldots, j_{n}}\left(x_{n 1}+j_{n} x_{n 2}\right)\right) \\
& \quad-\sum_{i_{1}, \ldots, i_{n} \in\{1,2\}} A_{i_{1}, \ldots, i_{n}} \frac{1}{A^{j}} f\left(\left(2 a_{1,1, \ldots, 1}\right)^{j} x_{\left.1 i_{1}, \ldots,\left(2 a_{n, 1, \ldots, 1}\right)^{j} x_{n i_{n}}\right), y \|}\right. \\
& \quad \leq \frac{\varepsilon}{|A|^{j}}
\end{aligned}
$$

for $\left(x_{11}, x_{12}, \ldots, x_{n 1}, x_{n 2}\right) \in X^{2 n}, y \in Y$ and $j \in \mathbb{N}_{0}$. Letting $j \rightarrow \infty$, and applying (17) and Remark 1 we deduce hence that the mapping $F: X^{n} \rightarrow Y$ is a solution of functional Eq. (3).

Let us finally suppose that $F^{\prime}: X^{n} \rightarrow Y$ is a solution of Eq. (3) such that inequality $(10)$ holds and $F^{\prime}\left(x_{1}, \ldots, x_{n}\right)=0$ for any $\left(x_{1}, \ldots, x_{n}\right) \in X^{n}$ with at least one component which is equal to zero. Then $F^{\prime}$ satisfies (18), and therefore it is a fixed point of the operator $T$. As in the proof of Theorem 3 we now conclude that $F^{\prime}=F$. 


\section{Some consequences}

Now, we present some consequences of Theorems 3 and 4 . First, we deduce from them a few outcomes on the stability of the functional equations mentioned in Sect. 2.

Let us start with the case $a_{11}=a_{12}=\ldots=a_{n 1}=a_{n 2}=1$ and $A_{i_{1}, \ldots, i_{n}}=1$ for $i_{1}, \ldots, i_{n} \in\{1,2\}$. Then from Theorem 3 we get the following outcome on the Ulam stability of functional equation (4) (see [18] and note that for $n=1$ it clearly means the stability of the Cauchy equation, which was investigated, among others, in $[10,14,15])$.

Corollary 5. Assume that $Y$ is a 2-Banach space and $\varepsilon>0$. If $f: X^{n} \rightarrow Y$ is a function satisfying

$$
\left\|f\left(x_{11}+x_{12}, \ldots, x_{n 1}+x_{n 2}\right)-\sum_{i_{1}, \ldots, i_{n} \in\{1,2\}} f\left(x_{1 i_{1}}, \ldots, x_{n i_{n}}\right), y\right\| \leq \varepsilon
$$

for $\left(x_{11}, x_{12}, \ldots, x_{n 1}, x_{n 2}\right) \in X^{2 n}$ and $y \in Y$, then there is a unique solution $F: X^{n} \rightarrow Y$ of Eq. (4) such that

$$
\begin{aligned}
& \left\|f\left(x_{1}, \ldots, x_{n}\right)-F\left(x_{1}, \ldots, x_{n}\right), y\right\| \leq \frac{\varepsilon}{2^{n}-1}, \\
& \left(x_{1}, \ldots, x_{n}\right) \in X^{n}, y \in Y .
\end{aligned}
$$

The mapping $F$ is given by

$$
F\left(x_{1}, \ldots, x_{n}\right):=\lim _{j \rightarrow \infty} \frac{f\left(2^{j} x_{1}, \ldots, 2^{j} x_{n}\right)}{2^{j n}}, \quad\left(x_{1}, \ldots, x_{n}\right) \in X^{n} .
$$

Let us next note that Theorem 3 is a generalization of Theorem 3.3 in [19], and thus its consequences are also some further results on the Ulam stability of a few known functional equations (see [19] for the details).

Theorem 3 with $n=1$ gives also obviously some stability outcomes on Eq. (6), and thus on its particular case $a_{1}=A_{1}, a_{2}=A_{2} \in \mathbb{N}$ which was studied in [3].

Now, we present some consequences of Theorem 4 .

Let us first consider the case $a_{1, j_{1}, \ldots, j_{n}}=\ldots=a_{n, j_{1}, \ldots, j_{n}}=1$ for $j_{1}, \ldots, j_{n} \in\{-1,1\}$ and $A_{i_{1}, \ldots, i_{n}}=2^{n}$ for $i_{1}, \ldots, i_{n} \in\{1,2\}$. Then from Theorem 4 we get the following outcome on the Ulam stability of functional equation (7) (see [22] and note that for $n=1$ it clearly means the stability of the Jordan-von Neumann equation, which was investigated, among others, in $[14,15,45])$.

Corollary 6. Assume that $Y$ is a 2-Banach space and $\varepsilon>0$. If $f: X^{n} \rightarrow Y$ is a function such that $f\left(x_{1}, \ldots, x_{n}\right)=0$ for any $\left(x_{1}, \ldots, x_{n}\right) \in X^{n}$ with at least one component which is equal to zero and

$$
\begin{gathered}
\| \sum_{j_{1}, \ldots, j_{n} \in\{-1,1\}} f\left(x_{11}+j_{1} x_{12}, \ldots, x_{n 1}+j_{n} x_{n 2}\right) \\
-\sum_{i_{1}, \ldots, i_{n} \in\{1,2\}} 2^{n} f\left(x_{1 i_{1}}, \ldots, x_{n i_{n}}\right), y \| \leq \varepsilon
\end{gathered}
$$


for $\left(x_{11}, x_{12}, \ldots, x_{n 1}, x_{n 2}\right) \in X^{2 n}$ and $y \in Y$, then there exists a unique solution $F: X^{n} \rightarrow Y$ of Eq. (7) such that $F\left(x_{1}, \ldots, x_{n}\right)=0$ for any $\left(x_{1}, \ldots, x_{n}\right) \in X^{n}$ with at least one component which is equal to zero and

$$
\begin{gathered}
\left\|f\left(x_{1}, \ldots, x_{n}\right)-F\left(x_{1}, \ldots, x_{n}\right), y\right\| \leq \frac{\varepsilon}{4^{n}-1}, \\
\left(x_{1}, \ldots, x_{n}\right) \in X^{n}, y \in Y .
\end{gathered}
$$

The mapping $F$ is given by

$$
F\left(x_{1}, \ldots, x_{n}\right):=\lim _{j \rightarrow \infty} \frac{f\left(2^{j} x_{1}, \ldots, 2^{j} x_{n}\right)}{4^{j n}}, \quad\left(x_{1}, \ldots, x_{n}\right) \in X^{n} .
$$
[21].

Let us next note that Theorem 4 is a generalization of Theorem 2 in

As for the Ulam stability of Eq. (8), Theorem 4 with $n=2, a_{1,1,1}=$ $a_{2,1,1}=a_{1,1,-1}=a_{2,1,-1}=a_{1,-1,1}=a_{2,-1,1}=a_{1,-1,-1}=a_{2,-1,-1}=1$ yields the following.

Corollary 7. Assume that $Y$ is a 2-Banach space, $|A|>1$ and $\varepsilon>0$. If $f: X^{2} \rightarrow Y$ is a function such that

$$
f\left(x_{1}, 0\right)=0=f\left(0, x_{2}\right), \quad\left(x_{1}, x_{2}\right) \in X^{2}
$$

holds and

$$
\begin{aligned}
& \| f\left(x_{11}+x_{12}, x_{21}+x_{22}\right)+f\left(x_{11}+x_{12}, x_{21}-x_{22}\right) \\
& \quad+f\left(x_{11}-x_{12}, x_{21}+x_{22}\right)+f\left(x_{11}-x_{12}, x_{21}-x_{22}\right) \\
& \quad-A_{1,1} f\left(x_{11}, x_{21}\right)-A_{1,2} f\left(x_{11}, x_{22}\right) \\
& \quad-A_{2,1} f\left(x_{12}, x_{21}\right)-A_{2,2} f\left(x_{12}, x_{22}\right), y \| \leq \varepsilon
\end{aligned}
$$

for $\left(x_{11}, x_{12}, x_{21}, x_{22}\right) \in X^{4}$ and $y \in Y$, then there exists a unique solution $F: X^{2} \rightarrow Y$ of Eq. (8) fulfilling condition (19) and

$$
\left\|f\left(x_{1}, x_{2}\right)-F\left(x_{1}, x_{2}\right)\right\| \leq \frac{\varepsilon}{|A|-1}, \quad\left(x_{1}, x_{2}\right) \in X^{2}, y \in Y .
$$

The mapping $F$ is given by

$$
F\left(x_{1}, x_{2}\right)=\lim _{j \rightarrow \infty} \frac{1}{A^{j}} f\left(2^{j} x_{1}, 2^{j} x_{2}\right), \quad\left(x_{1}, x_{2}\right) \in X^{2} .
$$

Finally, we derive from Theorem 4 the Ulam stability of the functional equations

$$
\begin{aligned}
& f\left(x_{11}+x_{12}, x_{21}+x_{22}\right)+f\left(x_{11}-x_{12}, x_{21}-x_{22}\right) \\
& \quad=2 f\left(x_{11}, x_{21}\right)+2 f\left(x_{11}, x_{22}\right)
\end{aligned}
$$

and

$$
\begin{aligned}
& f\left(x_{11}+x_{12}, x_{21}+x_{22}\right)+f\left(x_{11}+x_{12}, x_{21}-x_{22}\right) \\
& \quad=2 f\left(x_{11}, x_{21}\right)+2 f\left(x_{11}, x_{22}\right)+2 f\left(x_{12}, x_{21}\right)+2 f\left(x_{12}, x_{22}\right)
\end{aligned}
$$


(let us mention that the stability of Eq. (20) in Banach spaces was very recently studied in [31], whereas Eq. (21) was introduced and studied in [41]).

Theorem 4 with $n=2, a_{1,1,1}=a_{2,1,1}=a_{1,-1,-1}=a_{2,-1,-1}=1$, $a_{1,1,-1}=a_{2,1,-1}=a_{1,-1,1}=a_{2,-1,1}=0, A_{1,1}=A_{1,2}=2$ and $A_{2,1}=A_{2,2}=$ 0 gives the following outcome on the stability of Eq. (20).

Corollary 8. Assume that $Y$ is a 2-Banach space and $\varepsilon>0$. If $f: X^{2} \rightarrow Y$ is a function such that condition (19) holds and

$$
\begin{aligned}
& \| f\left(x_{11}+x_{12}, x_{21}+x_{22}\right)+f\left(x_{11}-x_{12}, x_{21}-x_{22}\right) \\
& \quad-2 f\left(x_{11}, x_{21}\right)-2 f\left(x_{11}, x_{22}\right), y \| \leq \varepsilon
\end{aligned}
$$

for $\left(x_{11}, x_{12}, x_{21}, x_{22}\right) \in X^{4}$ and $y \in Y$, then there exists a unique solution $F: X^{2} \rightarrow Y$ of Eq. (20) fulfilling (19) and

$$
\left\|f\left(x_{1}, x_{2}\right)-F\left(x_{1}, x_{2}\right), y\right\| \leq \frac{\varepsilon}{3}, \quad\left(x_{1}, x_{2}\right) \in X^{2}, y \in Y .
$$

The mapping $F$ is given by

$$
F\left(x_{1}, x_{2}\right)=\lim _{j \rightarrow \infty} \frac{1}{4^{j}} f\left(2^{j} x_{1}, 2^{j} x_{2}\right), \quad\left(x_{1}, x_{2}\right) \in X^{2} .
$$

On the other hand, applying Theorem 4 with $n=2, a_{1,1,1}=a_{2,1,1}=$ $a_{1,1,-1}=a_{2,1,-1}=1, a_{1,-1,1}=a_{2,-1,1}=a_{1,-1,-1}=a_{2,-1,-1}=0, A_{1,1}=$ $A_{1,2}=A_{2,1}=A_{2,2}=2$ we obtain the following.

Corollary 9. Assume that $Y$ is a 2-Banach space and $\varepsilon>0$. If $f: X^{2} \rightarrow Y$ is a function such that (19) holds and

$$
\begin{aligned}
& \| f\left(x_{11}+x_{12}, x_{21}+x_{22}\right)+f\left(x_{11}+x_{12}, x_{21}-x_{22}\right) \\
& \quad-2 f\left(x_{11}, x_{21}\right)-2 f\left(x_{11}, x_{22}\right)-2 f\left(x_{12}, x_{21}\right)-2 f\left(x_{12}, x_{22}\right), y \| \leq \varepsilon
\end{aligned}
$$

for $\left(x_{11}, x_{12}, x_{21}, x_{22}\right) \in X^{4}$ and $y \in Y$, then there exists a unique solution $F: X^{2} \rightarrow Y$ of Eq. (21) fullfiling (19) and

$$
\left\|f\left(x_{1}, x_{2}\right)-F\left(x_{1}, x_{2}\right), y\right\| \leq \frac{\varepsilon}{7}, \quad\left(x_{1}, x_{2}\right) \in X^{2}, y \in Y .
$$

The mapping $F$ is given by

$$
F\left(x_{1}, x_{2}\right)=\lim _{j \rightarrow \infty} \frac{1}{8^{j}} f\left(2^{j} x_{1}, 2^{j} x_{2}\right), \quad\left(x_{1}, x_{2}\right) \in X^{2} .
$$

Open Access. This article is licensed under a Creative Commons Attribution 4.0 International License, which permits use, sharing, adaptation, distribution and reproduction in any medium or format, as long as you give appropriate credit to the original author(s) and the source, provide a link to the Creative Commons licence, and indicate if changes were made. The images or other third party material in this article are included in the article's Creative Commons licence, unless indicated otherwise in a credit line to the material. If material is not included in the article's Creative Commons licence and your intended use is not permitted by 
statutory regulation or exceeds the permitted use, you will need to obtain permission directly from the copyright holder. To view a copy of this licence, visit http:// creativecommons.org/licenses/by/4.0/.

Publisher's Note Springer Nature remains neutral with regard to jurisdictional claims in published maps and institutional affiliations.

\section{References}

[1] Aczél, J., Dhombres, J.: Functional Equations in Several Variables. Cambridge University Press, Cambridge (1989)

[2] Aiemsomboon, L., Sintunavarat, W.: A note on the generalised hyperstability of the general linear equation. Bull. Aust. Math. Soc. 96, 263-273 (2017)

[3] Aiemsomboon, L., Sintunavarat, W.: On new approximations for generalized Cauchy functional equations using Brzdẹk and Ciepliński's fixed point theorems in 2-Banach spaces. Acta Math. Sci. 40, 824-834 (2020)

[4] Aoki, T.: On the stability of the linear transformation in Banach spaces. J. Math. Soc. Jpn. 2, 64-66 (1950)

[5] Bahyrycz, A., Ciepliński, K., Olko, J.: On an equation characterizing multiCauchy-Jensen mappings and its Hyers-Ulam stability. Acta Math. Sci. Ser. B (Engl. Ed.) 35, 1349-1358 (2015)

[6] Baias A.R., Popa, D., Raşa, I.: Ulam stability of a successive approximation equation. J. Fixed Point Theory Appl. 22, Paper No. 41 (2020)

[7] Becker, O., Lubotzky, A., Thom, A.: Stability and invariant random subgroups. Duke Math. J. 168, 2207-2234 (2019)

[8] Bourgin, D.G.: Classes of transformations and bordering transformations. Bull. Am. Math. Soc. 57, 223-237 (1951)

[9] Brzdęk, J., Cădariu, L., Ciepliński, K.: Fixed point theory and the Ulam stability. J. Funct. Spaces 2014, Art. ID 829419 (2014)

[10] Brzdȩk, J., El-Hady, E.-S.: On approximately additive mappings in 2-Banach spaces. Bull. Aust. Math. Soc. 101, 299-310 (2020)

[11] Brzdȩk, J., Popa, D., Raşa, I., Xu, B.: Ulam Stability of Operators. Academic Press, London (2018)

[12] Castro, L.P., Simões, A.M.: Hyers-Ulam-Rassias stability of nonlinear integral equations through the Bielecki metric. Math. Methods Appl. Sci. 41, 7367-7383 (2018)

[13] Cheng, L., Dong, Y.: A note on the stability of nonsurjective $\varepsilon$-isometries of Banach spaces. Proc. Am. Math. Soc. 148, 4837-4844 (2020)

[14] Cho, Y.J., Park, C., Eshaghi Gordji, M.: Approximate additive and quadratic mappings in 2-Banach spaces and related topics. Int. J. Nonlinear Anal. Appl. 3, 75-81 (2012)

[15] Chung, S.-C., Park, W.-G.: Hyers-Ulam stability of functional equations in 2-Banach spaces. Int. J. Math. Anal. (Ruse) 6, 951-961 (2012)

[16] Ciepliński, K.: Generalized stability of multi-additive mappings. Appl. Math. Lett. 23, 1291-1294 (2010)

[17] Ciepliński, K.: Applications of fixed point theorems to the Hyers-Ulam stability of functional equations - a survey. Ann. Funct. Anal. 3, 151-164 (2012) 
[18] Ciepliński, K.: Approximate multi-additive mappings in 2-Banach spaces. Bull. Iran. Math. Soc. 41, 785-792 (2015)

[19] Ciepliński, K.: On a functional equation connected with bi-linear mappings and its Hyers-Ulam stability. J. Nonlinear Sci. Appl. 10, 5914-5921 (2017)

[20] Ciepliński, K.: On Ulam stability of a functional equation. Results Math. 75, Paper No. 151 (2020)

[21] Ciepliński, K.: Ulam stability of a functional equation in various normed spaces. Symmetry 12 (2020)

[22] Ciepliński, K., Surowczyk, A.: On the Hyers-Ulam stability of an equation characterizing multi-quadratic mappings. Acta Math. Sci. 35, 690-702 (2015)

[23] Czerwik, S.: On the stability of the quadratic mapping in normed spaces. Abh. Math. Sem. Univ. Hamburg 62, 59-64 (1992)

[24] Diaz, J.B., Margolis, B.: A fixed point theorem of the alternative for contractions on a generalized complete metric space. Bull. Am. Math. Soc. 74, 305-309 (1968)

[25] Eilers, S., Shulman, T., Sørensen, A.P.W.: $C^{*}$-stability of discrete groups. Adv. Math. 373, 107324 (2020)

[26] El-Fassi, I., El-Hady, E., Nikodem, K.: On set-valued solutions of a generalized bi-quadratic functional equation. Results Math. 75, Paper No. 89 (2020)

[27] Fukutaka, R., Onitsuka, M.: Best constant for Ulam stability of Hill's equations. Bull. Sci. Math. 163, 102888 (2020)

[28] Gähler, S.: Lineare 2-normierte Räume. Math. Nachr. 28, 1-43 (1964)

[29] Gajda, Z.: On stability of additive mappings. Int. J. Math. Math. Sci. 14, 431-434 (1991)

[30] Guan, Y., Fečkan, M., Wang, J.: Periodic solutions and Hyers-Ulam stability of atmospheric Ekman flows. Discrete Contin. Dyn. Syst. https://doi.org/10. 3934/dcds.2020313

[31] Hwang, I., Park, C.: Ulam stability of an additive-quadratic functional equation in Banach spaces. J. Math. Inequal. 14, 421-436 (2020)

[32] Hyers, D.H.: On the stability of the linear functional equation. Proc. Natl. Acad. Sci. U.S.A. 27, 222-224 (1941)

[33] Hyers, D.H., Isac, G., Rassias, ThM: Stability of Functional Equations in Several Variables. Birkhäuser, Boston (1998)

[34] Ji, P., Qi, W., Zhan, X.: Generalized stability of multi-quadratic mappings. J Math. Res. Appl. 34, 209-215 (2014)

[35] Jung, S.-M.: Hyers-Ulam-Rassias Stability of Functional Equations in Nonlinear Analysis. Springer, New York (2011)

[36] Kannappan, Pl: Functional Equations and Inequalities with Applications. Springer, New York (2009)

[37] Kuczma, M.: An Introduction to the Theory of Functional Equations and Inequalities. Cauchy's Equation and Jensen's Inequality. Birkhäuser, Basel (2009)

[38] McKenney, P., Vignati, A.: Ulam stability for some classes of $C^{*}$-algebras. Proc. R. Soc. Edinb. Sect. A 149, 45-59 (2019)

[39] Monod, N.: An invitation to bounded cohomology. In: International Congress of Mathematicians, vol. II, pp. 1183-1211. Eur. Math. Soc., Zürich (2006)

[40] Park, W.-G., Bae, J.-H.: On a bi-quadratic functional equation and its stability. Nonlinear Anal. 62, 643-654 (2005) 
[41] Park, W.-G., Bae, J.-H., Chung, B.-H.: On an additive-quadratic functional equation and its stability. J. Appl. Math. Comput. 18, 563-572 (2005)

[42] Phochai, T., Saejung, S.: Some notes on the Ulam stability of the general linear equation. Acta Math. Hungar. 158, 40-52 (2019)

[43] Prager, W., Schwaiger, J.: Stability of the multi-Jensen equation. Bull. Korean Math. Soc. 45, 133-142 (2008)

[44] Rassias, ThM: On the stability of the linear mapping in Banach spaces. Proc. Am. Math. Soc. 72, 297-300 (1978)

[45] Sayar, K.Y.N., Bergam, A.: Approximate solutions of a quadratic functional equation in 2-Banach spaces using fixed point theorem. J. Fixed Point Theory Appl. 22, Paper No. 3 (2020)

[46] Skof, F.: Local properties and approximation of operators. Rend. Sem. Mat. Fis. Milano 53, 113-129 (1983)

[47] Zhao, X., Yang, X., Pang, C.-T.: Solution and stability of the multiquadratic functional equation. Abstr. Appl. Anal. 2013, Art. ID 415053 (2013)

Krzysztof Ciepliński

AGH University of Science and Technology, Faculty of Applied Mathematics

Mickiewicza 30

30-059 Kraków

Poland

e-mail: cieplin@agh.edu.pl

Accepted: April 28, 2021. 